\title{
TEMPORAL AND SPATIAL VARIATION OF FOREST COVERAGE IN APUSENI NATURAL PARK, 2000-2014 PERIOD
}

\author{
Paula FURTUNA
}

DOI: 10.21163/GT_2017.121.05

\begin{abstract}
:
Specific knowledge of forest cover change over a protected area, such as Apuseni Natural Park, is important for resource management, ecosystem quality and biodiversity protection. Landsat satellite imagery archive allows the annual changes characterization of forest cover over a long period of time. In the study area significant changes were detected in forest dynamic during the 2000-2014 period, it has been found, that around $15 \%$ of forests were disturbed during the period analysed. Spatial and temporal distributions of forest cover during the time period shows specific locations of forest loss, they are mainly spotted in the coniferous forest, and in the central part of the park. The overall accuracy was obtained $88.01 \%$, the lowest values obtained was for $2002(55.73 \%)$ and the higher for the year 2014 $(95.48 \%)$. The forest loss year-to-year revealed the higher loss rate for year 2007 (21.13\%).
\end{abstract}

Key-words: Forest variation, Apuseni Natural Park, Mountains regions, Forest loss.

\section{INTRODUCTION}

The forest has a crucial ecological role and the continuous forest loss can cause negative effects on the environment, (Janků et al., 2016). Forest protects plants and animals, offer protection for canopy and soil, and nevertheless play an important role in mitigation of climate change. Analyzing and detection of forest changes in protected areas is important for assessing the way in which biodiversity in these areas is conserved. In Romania after the restitution laws were adopted (in three stages), large areas of forest were returned to former owners, (Abrudan et al, 2009). These changes in forest law had have a fundamental impact in forest canopy, because the new owners decided to take immediate economic benefits by over exploitation, (Griffiths et al., 2014). Most of exploitation were not made based on a management plan, (Kuemmerle et al., 2006), and lead to forest fragmentation and replacement by other types of land cover. All these fragmentation and changes on forest canopy had an significant impact on landscape, (Huang et al., 2008). Analysis and quantifying all these changes are necessaries to detect the vulnerability of protected areas (to natural disturbance and human action) and to establish and develop a monitoring program in order to protect the biodiversity.

In the Apuseni Natural Park forest vegetation is constantly changing, recording a negative trend after the year 2000, (Knorn et al., 2012). A study concluded by Costea \& Haidu, (2010) revealed that in 2000 over $15 \%$ of the forest area was deforested compared to year 1988. This decreasing in forest vegetation cover has a negative impact over runoff (Costea et al, 2012), an increasing of flash-floods events on this region being recorder after the year 2002, (Haidu \& Costea, 2012). While general forest cover trend in Apuseni Natural Park are known, the changes occurred annually are lacking.

\footnotetext{
${ }^{1}$ Babes Bolyai" University, Faculty of Geography, 400006 Cluj Napoca, Romania, paula.roxana.furtuna@yahoo.com.
} 
In this study we focused on assessment of annual temporal and spatial forest cover changes (forest loss) across the Apuseni Natural Park from 2000 until 2014 using the Landsat data archive. Our main objectives were to (i): detect and assess the temporal and spatial variability of forest, and (ii) analyse the link between the forest variability and forest disturbance pattern. In this study we proposed an approach in which different remote sensing methods are combined to obtain accurate results regarding the annual forest changes. The forest disturbances (man-made and natural), are shaping constantly the forest and affects the structure and composition, (Dale et al., 2001). The assessment of socioeconomic effects on forest ecosystem is required and represents an important step for improving forest management in the region. And specific knowledge over protected areas helps to maintain a natural habitat and to protect biodiversity and natural landscape.

\section{DATA AND METHODS}

\subsection{Study area}

The study area is situated in the Western Romanian Carpathians, Apuseni Mountainswhich lies between the Pannonian Plain and Transylvanian Plateau.

The Apuseni Natural Park is situated in mountains with the same name (Apuseni Mountains, in the southern part of Bihor Mountains and the northern part Vladeasa Mountains), (Fig. 1). The park area is 75,784 hectares and it's lies on three counties (Cluj 40\%, Bihor 32\% and Alba - 28\%), (Purtan, 2010). The landscape is characterized by prolonged succession of gentle peaks, reaching maximum altitude in Păltinişului Hill (1785 $\mathrm{m}$ a.s.l. - above sea level) in the north of the park.
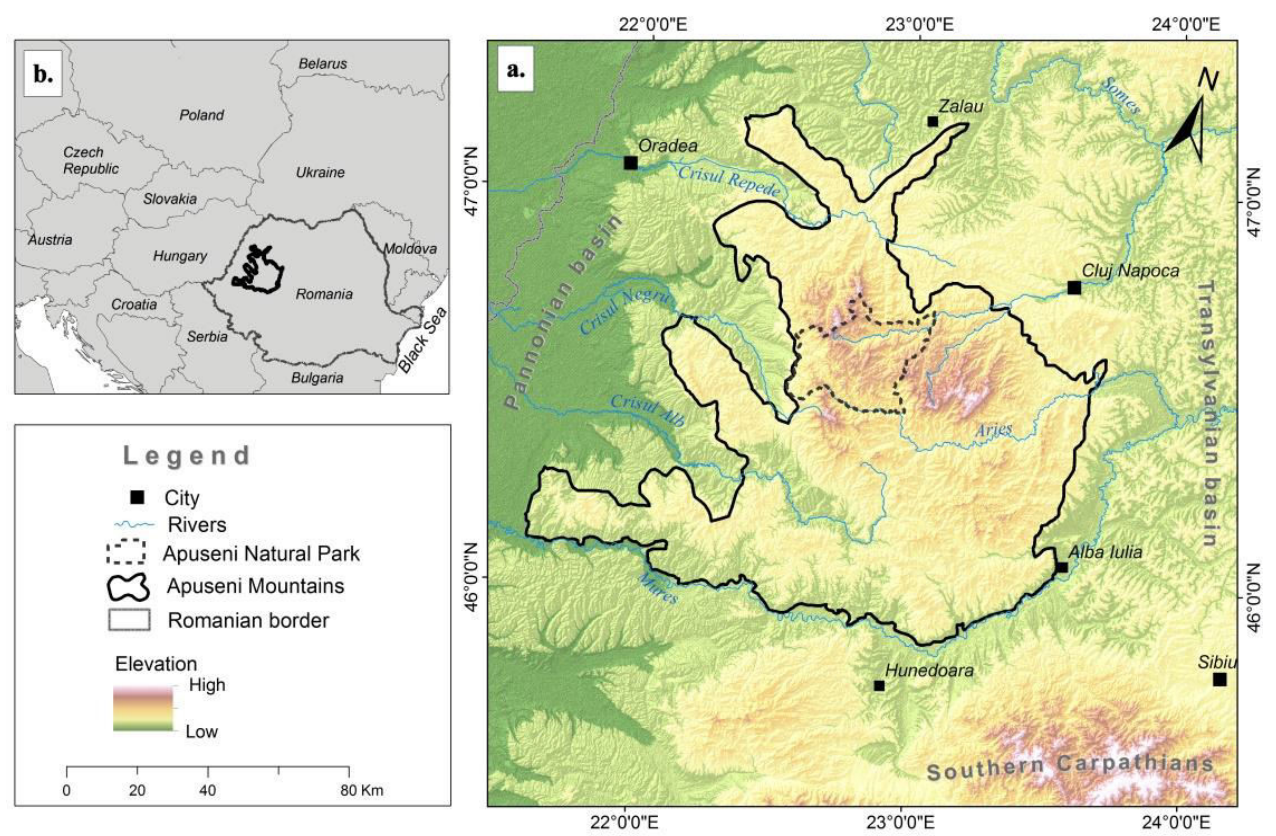

Fig. 1 a) Location of Apuseni Natural Park in the Apuseni Mountains; b) Location of the Apuseni Mountains within Romanian border. 
The vegetation is represented by specific-alpine mountain stage, (Purtan, 2010), distinguishing vertically in the following areas: mountain meadows, forests Spruce (Picea abies) and deciduous forests. Mountain forests are well developed between altitudes of $1200 \mathrm{~m}$ and $1600 \mathrm{~m}$ a.s.l , predominantly spruce and fir (Purtan, 2010). The climate is typical mountain one, wet and cold, with west prevailing winds, and average annual temperature registering $3^{\circ} \mathrm{C}$. The lower temperatures are recorded in January, with $-7^{\circ} \mathrm{C}$ on the high mountains and $-3^{\circ} \mathrm{C}$ in the and in lowlands. In July, the higher temperatures are recoding, with values between $10^{\circ} \mathrm{C}$ in highlands and $20^{\circ} \mathrm{C}$ in lowlands. The rainfalls increase with altitude, reaching a multi-annual mean over $1400 \mathrm{~mm}$ on high areas, (Mos, 2008).

\subsection{Data}

The availability of Landsat satellite imagery archive are representing a valuable source, and the development of data analysis methods offer a helpful data set in order to obtain better idea about long-term forest change patterns. The spatial and temporal analyses of forest in Apuseni Natural Park for 2000-2014 period was made based on Landsat satellite images (TM and ETM+, http://landsat.usgs.gov). Landsat program provide a continuous record of satellite images of the land surface at a medium resolution of $30 \mathrm{~m}$. The band RED, NIR and SWIR are representing an important tool to detect and mapping the forest changes. RED band is useful in discrimination of healthy vegetation, SWIR spectral band is sensitive to vegetation water content and soil moisture, while in the NIR band mature forests have lower reflectance values than non-forest vegetation, (Lu et al, 2008).

To conclude the study, a number of 16 Landsat scenes acquired from the growing season period, with clouds under the $10 \%$ were used. The use of dense time series of images will increase our ability to characterize the temporal variability and detect forest change with greater accuracy. Training and validation data was collected using Google Earth, there are available high resolutions images (Quick Bird, Ikonos, Digital Globe) and also forestry data represented by inventory tables of forestry, obtained from forest monitoring centres.

\subsection{Analysis}

The temporally dense satellite data can give a better idea about the trends in forests dynamics. Many studies stated that the use of dense (nearly annual) Landsat time series allows to detect the changes in the vegetation over a large area and over a large period of time (Cohen et al, 2010). Analysing forest disturbances on annual step offer a useful method to quantify and mapping the forest disturbance, and give the opportunity to identify factors that affects forest areas.

The Apuseni Mountains area was studies, including also the Apuseni Natural Park, most of these studies were undertaken to detected changes in land use. Forest change detection were made in order to highlight the deforestation over two periods of time 19882000 (Costea \& Haidu, 2010) where significant forest loss was detected. The vegetation indices were used to detect the vegetal cover changed over 1986-2009 period, (Furtuna et al., 2016), the result revealed important negative changes during 2000 and 2009. Also the supervised classification was used to evaluate land use changes over 36 years (1974-2010) (Costea, 2013), using images from four distinct periods.

This study provides an improved overview of forest changes across the Apuseni Natural Park emphasizing the annual changes over forest vegetation. The analysis of forest variation along the Apuseni Natural Park is important (being a protected area), in order to detect and quantify the changes occurred. Also is important because of the importance the 
tourism in the area and requires special attention. This analysis offers a summary of the forest distribution in 2000-2014 period.

The analysis was made based on an approach in which different remote sensing methods are combined with the purpose to obtain more accurate results regarding the annual forest changes. In order to achieve the objectives the main steps of research were developed ( $i$ ) data preparation and image pre-processing; (ii) image processing; (iii) detection and analysis of long term variability; (iv) evaluation of spatial distribution of forest change; $(v)$ validation of results.



Fig. 2 Workflow of analyse steps; (NDVI - Normalized Difference Vegetation Index, $\mathrm{Br}$ brightness band, Gr- greenness band, $\mathrm{Wr}$ - wetness band).

The main workflow steps for forest cover analysis started with pre-processing operations by calculating the root mean square error (RMSE) and by converting the digital number into surface reflectance, necessary to carry out the following operations (Fig.2).

Next step was to generate a forest map based on supervised classification for 2000 satellite image and forestry data which represented the basis for change detections. The images were acquired with less than $10 \%$ clouds, however some shadows remained and were masked to make sure that will not affect the analysis. This step was carried by using the NDVI values, thereby the pixels will be classified as water or dark soil if they have low reflectance in SWIR band and low values of NDVI.The "dark object" approach was used to obtain the annual forest cover for all imagery. This approach was proposed by Huang et al. (2008), and helped us to classified the images into forest and non-forest areas. The idea is 
that once water and dark soil is masked, (in previous step based on NDVI values), the pixels corresponding to forest areas will be located near the end of the image histogram. Next step consisted in finding the "forest peak" and setting a threshold based on this values, thereby the pixels associated to forest areas are automatically set, (Huang et al., 2008).

Also the Disturbance Index (DI) was calculating in order to improve the results of area with forest loss. This index is calculated based on the Brightness, Greenness and Wetness bands resulted from Tasselled Cap Transformation. The Tasselled Cap bands are sensitive to green vegetation abundance (greenness), canopy structure and moisture (wetness), and background soil signal (brightness), (Senf et al, 2015).

\section{RESULTS AND DISCUSSIONS}

Annual detection and the assessment of spatiotemporal variation of the forest in Apuseni Natural Park, during 2000-2014 were highlighted using "dark object" the Disturbance Index. Use of disturbance index allows us to detect forest disturbances defined in this study as both natural (winds and insects) and man-made (harvest or logging).

\subsection{Detection and assessment of spatiotemporal variations of the forest changes}

The trends in the forest areas inside the Apuseni Natural Park were derived using the images classified in forest/non-forest for each year (2000-2014). After that the forest pixels concentration was delineated, to achieve these step, the separability filters were used to detect how distinct and separable the values of forest pixels from non-forest pixels are, (Furtuna et al., 2015). The frequency filter was applied to 2000-2014 period time series imagery to show the spatial frequencies of each pixel for loss areas and to determine the number of pixels associated with the major forest loss trend.

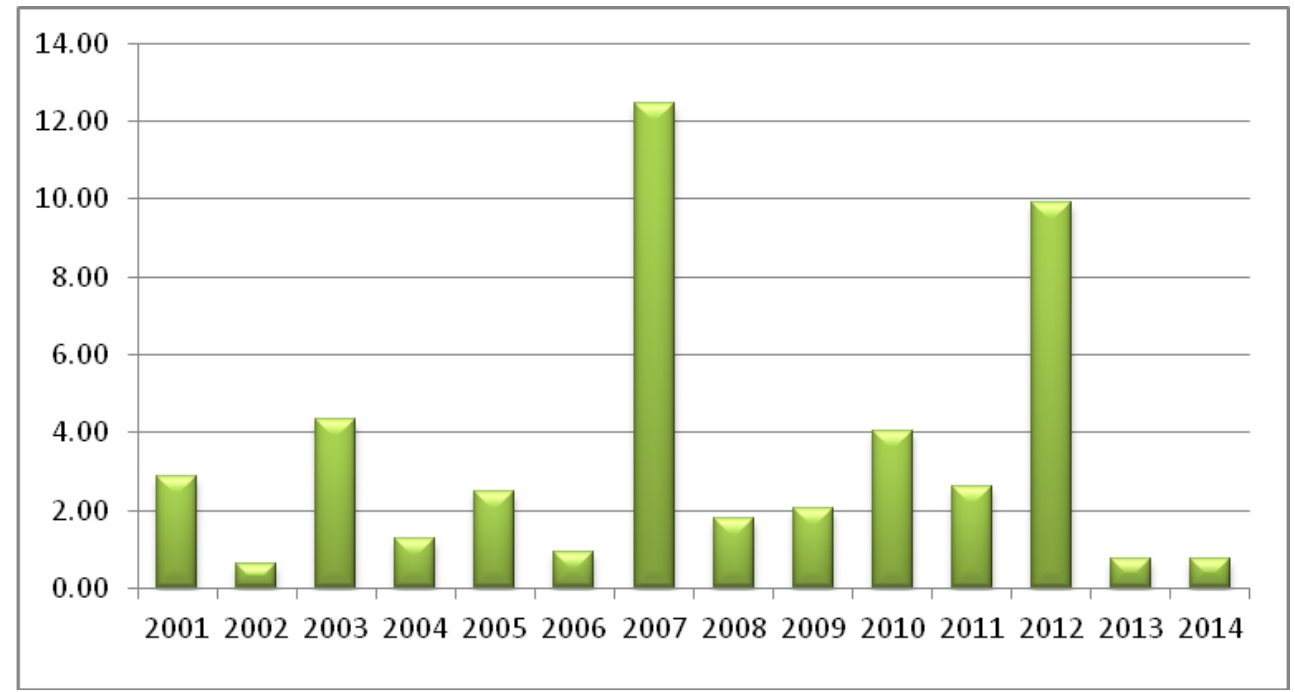

Fig. 3 Forest cover loss by year in the Apuseni Natural Park between 2001 and 2014.

The forest disturbances were defined, in this study, loss from one year to other, considering both human-induced and natural factors. Thereby the images were classified in constant forest, constant non-forest and forest loss. 
Constant forest and constant non-forest represent areas without changes from year-toyear detection while the forest loss represent the area were changes occur (in first image were forest areas and after turned into non-forest areas).

Once the classification was obtained, a confusion matrix was calculated with overall accuracy $88.01 \%$, the lowest values obtained was for 2002 and the higher for 2014. After ratio and differences calculation between images were made and the result was the areas with forest loss year-to-year. The highest rate of forest loss was recorded in 2007 (21.13 $\%$ ), (Fig. 3).

\subsection{Forest disturbance detection}

The detection of forest loss was made based on Disturbance Index (DI) values, developed by Healey et al (2005). This index was used in order to improve the forest cover dynamic detection. DI was developed in order to emphasize spectral signatures of disturbed areas, (Healey et al, 2005). The idea behind the index is that disturbance sites show high values in brightness and low values in wetness, and greenness bands compared to undisturbed forests, (Baumann et al, 2014). The DI is calculated based Tasseled-Cap bands, using following formula:

$$
D I=B_{r}-\left(G_{r}+W_{r}\right)
$$

where: $\mathrm{Br}, \mathrm{Gr}, \mathrm{Wr}$ are the Tasseled Cap bands, standardized around the scene's mean forest pixels.

The result represents one single band. Where are positive values indicate, generally, the areas where the forest where disturbed. Figure 4 highlights the values of Disturbances Index obtained for 200-2014 period. In the Fig. 4a is highlighted an area with forest loss for the analysed period, and in Fig. 4d the DI values for the chosen point for 2011.

After the calculation of DI it is necessary to set a threshold to make the result easy to interpret, (Healey et al, 2005). Several threshold were applied to established which values identify better the forest loss areas, and was set the DI $=2.5$ values. It has been found that around $15 \%$ of forests were disturbed during the study period, mostly in conifers areas. The spatial distribution of forest cover change during the time period shows specific locations of forest loss. They are mainly spotted in the coniferous forest and the largest areas were affected in 2007 (Fig. 5; Fig. 6). The last steps was to combined the forest loss images with the DI map and we obtained a map with the forest loss during 2000-2014

\subsection{Discussions}

Despite the medium-resolution offered by Landsat sensors, these satellite images represents an important tools in order generate accurate forest cover dynamic over a long period of time. While using Landsat data offer an aerial image over the studied area the ground date and local knowledge about forest have a key role for better understand the forest trend. The study highlights the benefits of using Landsat satellite imagery to detect, quantify and understand the trend in land cover change in forest environments. Vogelmann et al. (2012) discuss the use of Landsat imagery for forest change analysis and they depict that Landsat imagery is applicable for detecting abrupt and gradual ecosystem changes. 


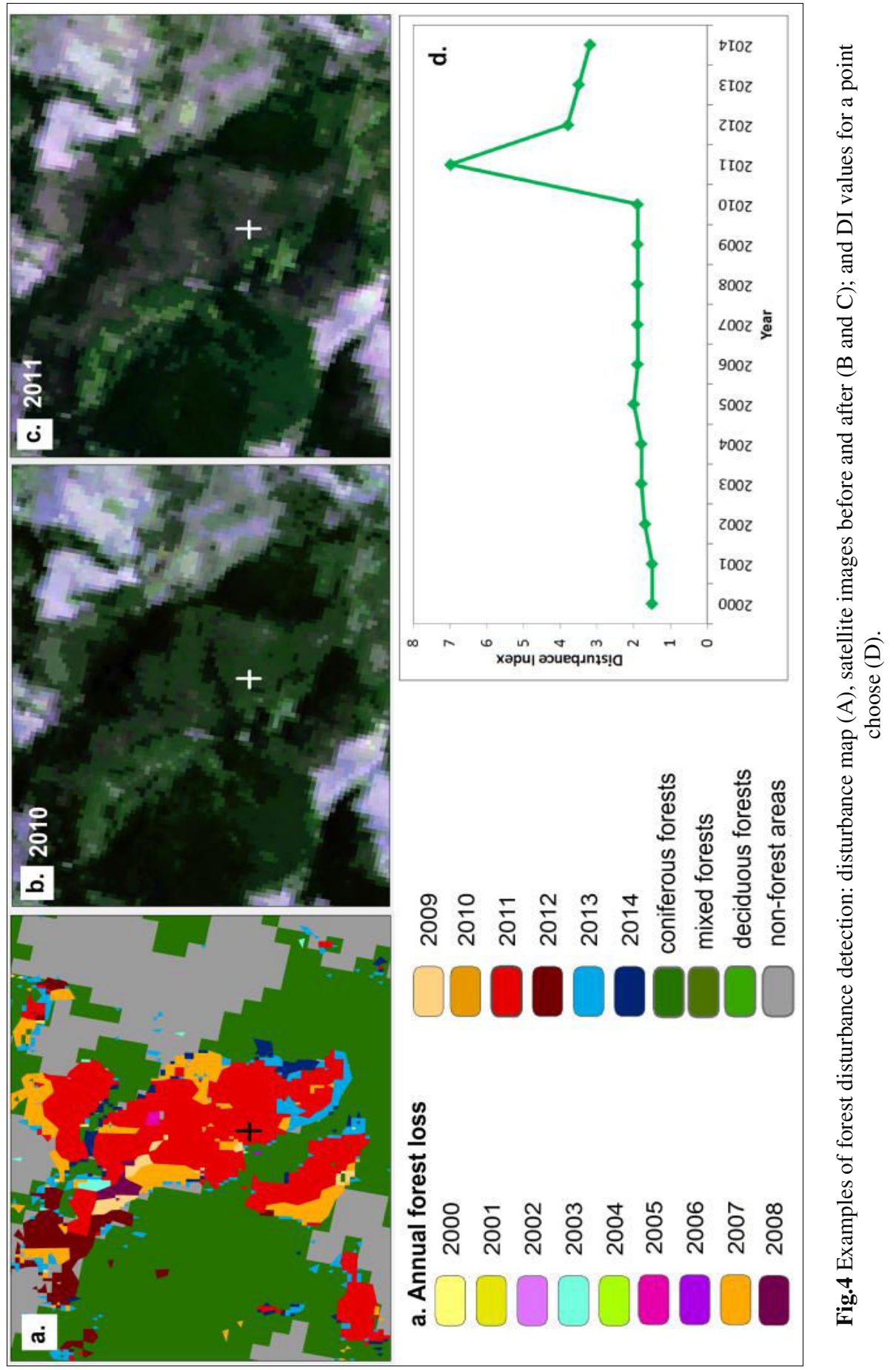


$N$

L e g e n d

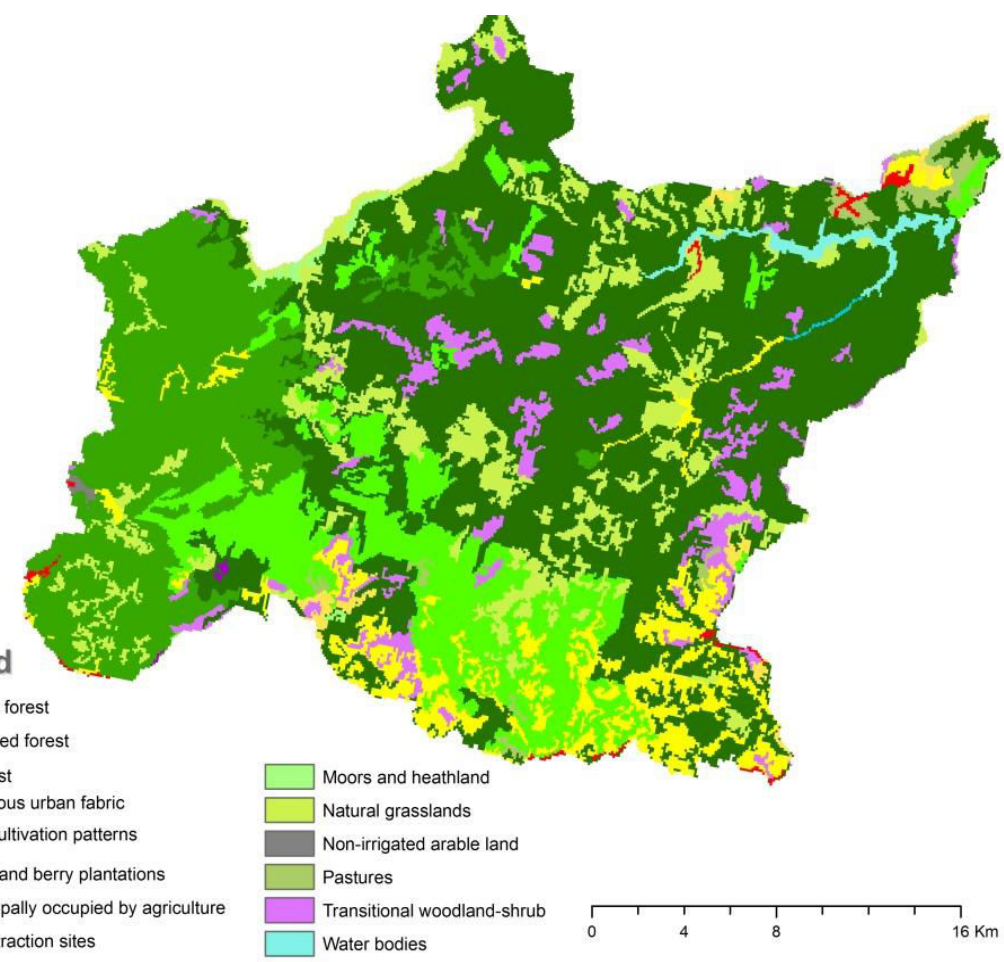

Fig. 5 Land cover in the Apuseni Natural Park.



Fig. 6 Forest loss by year in the Apuseni Natural Park between 2001 and 2014. 
However in order to get more accurate result among forest disturbance is recommended to use annual time series images. Also the annual forests variation and weather condition on plant activity can influence the results obtained using remote sensing and satellite images, (Forkel et al., 2013). Nevertheless the result obtain in this study, is reinforced by the results obtained by Costea \& Haidu, (2010); Haidu \& Costea, 2012; Costea, (2013) which highlighted the decreasing trend upon the forest cover. The overall forest areas in Apuseni Natural Park are constantly decreasing.

The DI values demonstrate a high sensitivity to identify forest disturbance and estimate the areas with forest loss and the using on annual images allowed us to map year-to-year forest loss. In Fig. 6 are highlighted these areas. It can be observed that there is a trend in the location of forest loss, mainly are located in the central part of the park. In this part of the park are located important tourist attractions, like Padis Plateau, Belis area. The higher forest loss was recorded in 2007, and followed by the year 2012. The last 2 years (2013 and 2014) analysed are shown a low percentages of forest loss.

Validation of the changes in land cover detected based on Landsat data is challenging (Kayastha et al, 2012), and sometimes requires to collect references dataset from the ground. In the study, we used available high spatial resolution aerial images from Google Earth to interpret the validation polygons. To achieve this step, 21 polygons were used, which depict the forest loss in the study area. Also, 300 points were used to validate the supervised classification, for year 2000 forest map, these points were labelled manually using images from Google Earth. The overall accuracy obtained was $80.23 \%$ and kappa statistic $0.88 \%$. In addition, the reports from the forest monitoring centres and the historical data of forest cover dynamics were made use of. The resulted forest disturbance layers were clipped with ground truth polygons.

Table 1.

Error matrix for 2000-2014, presented user and producer's accuracy for "CF - constant forest", "CNF - constant non-forest" and "FL - forest loss".

\begin{tabular}{|c|c|c|c|c|c|c|c|c|}
\hline & \multicolumn{3}{|c|}{ User's } & \multicolumn{3}{|c|}{ Producer's } & \multirow{2}{*}{$\begin{array}{c}\text { Overall } \\
\text { accuracy }\end{array}$} & \multirow{2}{*}{$\begin{array}{l}\text { Kappa } \\
\text { statistic }\end{array}$} \\
\hline & CF & CNF & FL & CF & CNF & FL & & \\
\hline 2001 & 48.50 & 70.20 & 69.23 & 68.37 & 76.95 & 66.52 & 66.63 & 0.67 \\
\hline 2002 & 60.42 & 52.36 & 52.25 & 54.16 & 58.35 & 55.34 & 55.73 & 0.60 \\
\hline 2003 & 74.16 & 90.12 & 88.23 & 78.23 & 93.14 & 87.02 & 85.15 & 0.89 \\
\hline 2004 & 73.71 & 83.56 & 82.65 & 76.58 & 87.98 & 86.89 & 81.90 & 0.79 \\
\hline 2005 & 58.74 & 89.65 & 79.56 & 68.95 & 88.65 & 91.25 & 79.47 & 0.81 \\
\hline 2006 & 52.59 & 84.25 & 82.52 & 72.35 & 87.23 & 82.98 & 76.99 & 0.77 \\
\hline 2007 & 74.39 & 91.35 & 88.95 & 93.54 & 92.56 & 90.02 & 88.47 & 0.90 \\
\hline 2008 & 37.87 & 88.12 & 82.36 & 76.23 & 89.65 & 80.23 & 75.74 & 0.77 \\
\hline 2009 & 61.23 & 90.36 & 79.65 & 70.58 & 91.65 & 88.65 & 80.35 & 0.81 \\
\hline 2010 & 63.89 & 87.65 & 78.93 & 73.72 & 85.93 & 81.25 & 78.56 & 0.79 \\
\hline 2011 & 80.23 & 89.56 & 87.65 & 82.12 & 92.15 & 90.75 & 87.08 & 0.89 \\
\hline 2012 & 79.74 & 90.25 & 89.47 & 76.37 & 92.98 & 88.96 & 86.30 & 0.90 \\
\hline 2013 & 87.88 & 83.65 & 74.65 & 87.37 & 86.35 & 76.25 & 82.69 & 0.89 \\
\hline 2014 & 94.81 & 96.29 & 95.36 & 93.12 & 97.53 & 95.78 & 95.48 & 0.92 \\
\hline
\end{tabular}


Therefore, to obtain a better understanding of map accuracy, we calculate the error matrix, for annual classification into constant forest, constant non forest and constant other classes. For each year 150 random points were selected within the classification classes. To establish the classification accuracy the user's and producer's accuracy as well as overall accuracy and kappa statistics were used, (Table 1). The higher user and producer's values were obtained for constant non-forest class, while the lowest values were obtained for constant forest class.

These result emphasize that the area which are not cover with forest vegetation are easily and more accurate to detect using Landsat satellite imagery. The lower values for accuracy indices were obtain for year 2002, overall accuracy 55.73\%, kappa statistic $0.60 \%$. For this year the higher value was obtain for user's constant-forest class.

\section{CONCLUSIONS}

The goal of our study was to analysis the spatial and temporal forest cover dynamics within Apuseni Natural Park over 14 years (2000-2014). Through analysis of annual Landsat satellite imagery, we found significant change in forest cover during the 2000-2014 periods. It has been found, that around $15 \%$ of forests were disturbed. The spatial distributions of forest cover change during 2000-2014 period shows specific locations of forest loss, they are mainly spotted in the coniferous forest and in the central part of the park. This is an important fact because the central part of the park is continuously developing due to the touristic attraction in this region. In the same time, with touristic development, other sectors are developing, some in a positive way other in a negative way. The development of road infrastructure and tourism sectors can contribute to the economic and social development of park area. However, this development has a significant impact on the evolution of the forest sector.

The resulted trend map had some misleading areas with forest loss in areas where there wasn't covered by forest. The confusion matrix errors show that the constant forest class recorded the lowest values, while the constant non-forest class recorded the highest values.

The DI values calculate base on Landsat images demonstrate the high sensitivity for identify forest disturbance and effectively estimated the areas with forest loss.

\section{R E F E R E N C E S}

Abrudan, I. V., Marinescu, V. \& Ionescu, O. (2009) Development in the romanian forestry and its linkages with other sectors. Notulae Botanicae Horti Agrobotanici, 37(2), 14-21.

Baumann, M., Ozdogan, M., Wolter, P. T., Krylov, A., Vladimirova, N. \& Radeloff, V. C. (2014) Landsat remote sensing of forest windfall disturbance. Remote Sensing of Environment, 143, 171-179.

Cohen, W. B., Yang, Z. \& Kennedy, R. (2010) Detecting trends in forest disturbance and recovery using yearly Landsat time series: 2 . TimeSync - Tools for calibration and validation. Remote Sensing of Environment, 114, 2911-2924.

Costea, G. (2013) Deforestation process consequences upon surface runoff coefficients, catchment level case study from the Apusnei Mountains, Romania. Geographia Technica, 8 (1), 28-33.

Costea, G., Serradj, A., Haidu, I. (2012) Forest cartography using Landsat imagery, for studying deforestation over three catchments from Apuseni Mountains, Romania. In: Advances in Remote Sensing, Finite Differences and Information Security. Proceedings of the 8th WSEAS International Conference on Remote Sensing, ISBN: 978-1-61804-127-2, 109-114. [Online] Available from: http://www.wseas.us/e-library/conferences/2012/Prague/ISFINRE/ISFINRE-17.pdf 
Costea, G. \& Haidu, I. (2010) Detection of recent spatial changes regarding landuse in small basins from the Apuseni Natural Park. Geographia Technica, 5 (2), 11-17.

Dale, V. H., Joyce, L. A., Mcnulty, S., Neilson, R. P., Ayres, M. P., Flannigan, M. D., Hanson, P. J., Irland, L. C., Lugo, A. E., Peterson, C. J., Simberloff, D., Swanson, F. J., Stocks, B. J. \& Wotton, B. M. (2001) Climate Change and Forest Disturbances, BioScience, 51 (9), 723-734.

Forkel, M., Carvalhais, N., Verbesselt, J., Mahecha, M., Neigh, C. \& Reichstein, M. (2013) Trend Change Detection in NDVI Time Series: Effects of Inter-Annual Variability and Methodology. Remote Sensing, 5 (5), 2113-2144.

Furtuna, P., Haidu, I., Alexe, M. \& Holobaca, I. (2016) Change Detection in the Cluj forest district, using remote sensing and GIS application. Environmental Engineering and Management Journal, 15 (6), $1361-1368$.

Furtuna, P., Haidu, I., Holobaca, I. H., Alexe, M., Rosca, C. \& Petrea, D. (2015) Assessment of the forest disturbances rate caused by windthrow using remote sensing techniques. In: Progress in Electromagnetic Research Symposium. Proceedings of the PIERS 2015, Prague, Czech Republic, ISBN: 978-1-934142-30-1, 162-166. [Online] Available from: http://piers.org/piersproceedings/piers2015PragueProc.php.

Griffiths, P., Kuemmerle, T., Baumann, M., Radeloff, V. C., Abrudan, I. V., Lieskovsky, J., Munteanu, C., Ostapowicz, K. \& Hostert, P. (2014) Forest disturbances, forest recovery, and changes in forest types across the carpathian ecoregion from 1985 to 2010 based on landsat image composites. Remote Sensing of Environment, 151, 72-88.

Haidu, I. \& Costea, G. (2012) Remote sensing and GIS for the forest structure assessment at the small basins' level in the Apuseni Natural Park. Studia UBB Geographia, 57(1), 81-88.

Healey, S. P., Cohen, W. B., Zhiqiang, Y. \& Krankina, O. N. (2005) Comparison of Tasseled Cap-based Landsat data structures for use in forest disturbance detection. Remote Sensing of Environment, 97, 301-310.

Huang, C., Song, K., Kim, S., Townshend, J. R. G., Davis, P., Masek, J. G. \& Goward, S. N. (2008) Use of a dark object concept and support vector machines to automate forest cover change analysis. Remote Sensing of Environment, 112 (3), 970-985.

Janků, J., Jakšík, O., Kozák, J. \& Marhoul, A. M. (2016) Estimation of land loss in the Czech Republic in the near future. Soil and Water Research, 11 (3), 155-162.

Kayastha, N., Thomas, V., Galbraith, J. \& Banskota, A. (2012) Monitoring wetland change using interannual landsat time-series data, Wetlands, 32 (6), 1149-1162.

Knorn, J., Kuemmerle, T., Radeloff, V. C., Szabo, A., Mindrescu, M., Keeton, W. S., Abrudan, I., Griffiths, P., Gancz, V. \& Hostert, P. (2012) Forest restitution and protected area effectiveness in post-socialist Romania, Biological Conservation, 146 (1), 204-212.

Kuemmerle, T., Radeloff, V. C., Perzanowski, K. \& Hostert, P. (2006) Cross-border comparison of land cover and landscape pattern in Eastern Europe using a hybrid classification technique. Remote Sensing of Environment, 103 (4), 449-464.

Lu, D., Batistella, M., Li, G., Moran, E., Hetrick, S., Freitas, C. da C., Dutra, L. V. \& Sant'Anna, S. J. S. (2008) Integration of Landsat TM and SPOT HRG Images for Vegetation Change Detection in the Brazilian Amazon. Photogramm Eng Remote Sensing, 74 (4), 421-430.

Mos, A. (2008) Apuseni Nature Park - a park for nature and people. Analele Universităţii din Oradea, Seria Geografie, 18, 21-26.

Purtan, M. (2010) Parcul Natural Apuseni - Dezechilibrele environmentale cauzate de activitatea antropica. Oradea, ISBN: 978-973-0-08544-0. [Online] Available from: http://documente.bcucluj.ro/web/bibdigit/publicatiicd/489414/489414.html.

Senf, C., Dirk, P., Wulder, M. A. \& Hostert, P. (2015) Characterizing spectral - temporal patterns of defoliator and bark beetle disturbances using Landsat time series. Remote Sensing of Environment, $170,166-177$.

Vogelmann, J. E., Xian, G., Homer, C. \& Tolk, B. (2012) Monitoring gradual ecosystem change using Landsat time series analyses: Case studies in selected forest and rangeland ecosystems. Remote Sensing of Environment, 122, 92-105. 